\title{
Investigating and analyzing the most important delay causes in Kurdistan Building Construction Projects
}

\author{
Sevar Neamat \\ Department of Mechanical Engineering, University of Zakho, Kurdistan Region-Iraq, Sevar.Dilkhaz@uoz.edu.krd
}

\begin{abstract}
The most controversial trouble that happened in the construction projects is Delay. So, the specified research took part to investigate the basic causes in delaying the Kurdistan Region of Iraq. The study gathered information from the insight of contractors, consultants, and owners. A wide literature review has been discussed. The delay causes are recognized built on the identified literature review. These features are characterized into owner-related, consultant-related, contractor-related, material-related, labour and equipment-related, and external-related groups. Twenty- six experienced persons participated in doing the questionnaire surveys to control the relative importance of every cause. The work discovered that the highest five reasons for postponement in building projects are financial difficulties by contractors, variation in prices, postponement in making and appreciative shop diagrams, lack of labour, and mistakes in soil study. Lastly, the probable approaches of dropping plan postponements are suggested. This work helps as a helpful tool for construction experts and academics to prevent reasons for postponement in constructing schemes in Kurdistan.
\end{abstract}

Keywords: Delay, Building projects, Relative importance index, Recommendations, Kurdistan Region of Iraq

Received: March 28, 2021 / Accepted: June 01, 2021 / Online: June 4, 2021

\section{INTRODUCTION}

One of the most significant contributions of Kurdistan development is the construction industry [1], [2]. The project considered successful by completing the requirement on time and within inexpensive accomplishment. Also, it has to fulfil the stipulations and safeguard the investors' gratification. Though, the doubt and individuality related to constructing schemes will possibly lead to their late distributions. In the paper titled by numbers [3], [4], the researchers specified that $76 \%$ of contractors and $56 \%$ of consultants are facing a regular period swarming of 10 to $30 \%$ that reasons a $50 \%$ cost swarming. It was stated that $50 \%$ of the construction schemes in the United Arab Emirates met the construction postponement [5]. Consequently, postponement is measured as one of the greatest shared difficulties which result in an assembly of undesirable properties on construction projects [6].

Delay definition is time overrun of the plan completion date. As well, it results in losing the income after the possessor's viewpoint resulted in the absence of creative services and rentable space [7], [8]. After the contractor's viewpoint, postponement produces an advanced upstairs budget for the reason of developed the substantial prices over deflation, lengthier employed areas, and sophisticated work expenses. So, the delay might harmfully influence the scheme period, cost, and quality [9]. The chief reasons for postponement might be brief as follows: technical matters, usual situations, and difficulties connected to the owner, subcontractor, or contractor [10]. The reasons for postponement should be well got and examined to take the essential activities that stop their incidences as of the first place [11]. Then, this investigates purposes at classifying the main bases of scheme postponement in the constructing subdivision as well as the corrective measures for delays [12].

Finalizing the plans on period is a pointer of talented progress industry [13]. Also, the postponement as a factor has been investigated in these papers [14], [15],[16] which negotiate the important of considering such a factor in the Kurdistan region of Iraq construction projects. In order to design and contract with an operative job, the three parameters of time, cost and quality must to be measured, [17]. In Kurdistan Region of Iraq, the improvement of business is the greatest notable follower of the monetary progress. The highest client of the progress business is administration of open jobs plans. These projects are enormous for close grid and should be carried on timetable. Any delay in transportation won't improve the complete incentive overdue of jobs' application effort in the development idea. Amongst all achievement plans the Design and Build (D\&B) projects is notable in completing development extends in Kurdistan Region of Iraq and various nations.

The responsibility managements and the group should understand the materials resulting these delays and rate the

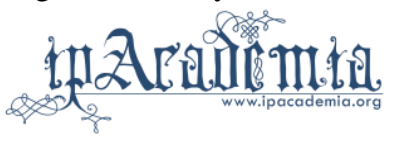


encouragement scheme dissatisfactions. The quantitative inspection of survey review will neglect down the danger producing issues by locating. This will aid the job administrators and the experts to produce active transfer to such dissatisfaction conditions.

\section{PROBLEM STATEMENT}

Many construction projects are available in the Kurdistan Region of Iraq [18]. In order to figure out the state, there should be various structures, roads, bridges, etc. with quick flights. Nonetheless, here it appears to be gradually overdue for numerous causes. Numerous persons have considered in this respect. Nevertheless no one appears to have supposed around falling it. So, I have equipped the specific research on the suggestion organized by reviewing the main causes of construction time. Also, the cost payment delay with watching to in which way this can be minimized.

Later, directly the study must be accomplished on the cause and influence of postponement achievement of various construction projects in Kurdistan Region of Iraq [2]. I have realized this research is absolutely essential to finalize the subsequent responsibilities.

- Discover the key goal illustrating in which approach the construction work is late.

- To speediness the construction effort rapidly, no cause to derive.

- Studying the factors of postponement in construction and investigating timely way.

Additionally, there are various danger issues imposing cost inside the construction work. Subsequently, predictors tend to carry this matter in order to investigate with the determination of distinguishing the fundamentals and their placing of importance

\section{LITERATURE REVIEW}

Many types of research been prepared to evaluate the postponement reasons in constructing projects everywhere in the world. This investigation has been directed in various nations since the delay issues vary from one republic to one more, from one time to another, and from one scheme to another [19]. Marzouk and El-Rasas examined the most significant postponement sources in the Egyptian constructing plans utilizing incidence catalogue, harshness index, and importance index.

The postponement features were well-ordered in the subsequent order: owner-related, contractor-related, externalrelated, consultant-related, labour and equipment-related, project-related, and material-related factors. Amoatey et al tried to examine the postponement reasons and impacts in Ghanaian housing constructing schemes using relative importance index (RII) and correlation analysis. The greatest dangerous postponement issues were specified as follows: postponement in payment to contractor/supplier, inflation/price fluctuation, the enlarged value of resources, funding from the sponsor/client, difference instructions, and poor monetary market [20], [21].
Larsen et al in their paper [22] evaluated the effect of delay matters on the time, cost, and quality of public construction schemes. Additionally, the delay subjects remained classified employing the RII and confirmed through Friedman's and Wilcoxon's tests. The authors documented the five main details of delay as lack of money, postponement produced by other establishments, poor planning, errors or oversights in constructing work, and difficulties in the documentation of needs [8], [23].

Durdyev et al evaluated the contractors and consultants insights on delay causes of the relative importance in the Cambodian construction industry by RII [24]. The outcomes of the research illustrated that lack of materials on-site, impractical project preparation, Materials late submission, lack of expert workers, the difficulty of projects, labour absence, not on-time payment to workers by the owner when the project finished, deprived site organization, postponement by the subcontractor, and chances on-site are ordered as the chief reasons of project postponements in Cambodia. The researchers determined that the powerful reasons for postponement are dishonesty, inaccessibility of services at workplaces, price rises, highly cost of materials, the deficiency of good materials, delay issue of design documents, slow transfer of constituents, not on time agreement and reception of finished effort, deprived site administration and performance, not on time announcement of budget/funds, and unproductive project preparation and arrangement [25][26].

Soliman in his paper [27] examined the postponement causes in Kuwait constructing plans and the probable approaches to stop their incidence and alleviate their impacts. The endorsements included alterations of contract sections, modification of awarding schemes, lack of the documented period, and alteration of contract forms. Shahsavand et al. [9] exposed the chief reasons for postponement in the Iranian constructing schemes from the client's, consultant's, and contractor's perspective. The relative significance of these reasons was assessed using RII and a statistical package for social sciences (SPSS). The postponement features were ordered in the subsequent instruction: client-correlated, worker and equipment-related, contractor-correlated, material-correlated, design-correlated. outside, and consultant-related issues.

Alsuliman examined the reasons for postponements in community constructing schemes in Saudi Arabia. The reasons for postponement were separated into three groups specifically, issues before the award of proposals, issues throughout the prize of tenders, issues afterwards the award of proposals, and general issues. The impact of these influences on the agenda postponement was designed utilizing a basic formula. Hossain et al examined the reasons for postponements in various kinds of Kazakhstan's construction projects. Also, the postponement issues were considered dependent on the changed views of scheme parties. Lastly, the references and remedial actions for the postponements were provided. 
TABLE I. DELAY CAUSES IN CONSTRUCTION PROJECTS COLLECTED FROM THE LITERATURE

\begin{tabular}{|c|c|c|c|c|c|c|}
\hline No. & Causes of Delay & $\begin{array}{c}\text { Kazaz et al. } \\
{[17]}\end{array}$ & $\begin{array}{l}\text { Marzouk and } \\
\text { El-Rasas [10] }\end{array}$ & $\begin{array}{c}\text { Owolabi et al. } \\
{[18]}\end{array}$ & $\begin{array}{c}\text { Bekr } \\
{[19]}\end{array}$ & $\begin{array}{l}\text { Srdić and Šelih } \\
{[20]}\end{array}$ \\
\hline 1 & Delay in reviewing documents & & $\checkmark$ & & & $\checkmark$ \\
\hline 2 & Monetary difficulties by the contractor & $\checkmark$ & $\checkmark$ & $\checkmark$ & $\checkmark$ & \\
\hline 3 & Late expense by the holder for the finished work & $\checkmark$ & $\checkmark$ & $\checkmark$ & $\checkmark$ & \\
\hline 4 & Design variations & $\checkmark$ & & $\checkmark$ & $\checkmark$ & $\checkmark$ \\
\hline 5 & Late delivery of resources & & $\checkmark$ & & $\checkmark$ & \\
\hline 6 & Alteration in agreement & $\checkmark$ & & $\checkmark$ & & \\
\hline 7 & Inappropriate organization among project gatherings & $\checkmark$ & $\checkmark$ & $\checkmark$ & $\checkmark$ & \\
\hline 8 & Slow decision creation & & $\checkmark$ & $\checkmark$ & $\checkmark$ & $\checkmark$ \\
\hline 9 & $\begin{array}{l}\text { Postponement in the preparation and positive shop } \\
\text { sketches }\end{array}$ & & $\checkmark$ & & $\checkmark$ & $\checkmark$ \\
\hline 10 & Lack of resources & & $\checkmark$ & & $\checkmark$ & \\
\hline 11 & Deprived workplace organization & $\checkmark$ & $\checkmark$ & & $\checkmark$ & $\checkmark$ \\
\hline 12 & Inappropriate organization of holder & & & & $\checkmark$ & $\checkmark$ \\
\hline 13 & Poor invention rate of workers & $\checkmark$ & $\checkmark$ & & $\checkmark$ & \\
\hline 14 & Errors in constructing of building & $\checkmark$ & $\checkmark$ & $\checkmark$ & $\checkmark$ & \\
\hline 15 & Errors in plans & & & & $\checkmark$ & \\
\hline 16 & Lack of equipment & & & $\checkmark$ & $\checkmark$ & \\
\hline 17 & Lack of workers & $\checkmark$ & $\checkmark$ & & $\checkmark$ & \\
\hline 18 & Errors in soil study & & & & $\checkmark$ & \\
\hline 19 & Inexpert workers & & $\checkmark$ & & & $\checkmark$ \\
\hline 20 & Struggles between project parties & $\checkmark$ & $\checkmark$ & $\checkmark$ & $\checkmark$ & \\
\hline 21 & Improper weather circumstances & $\checkmark$ & $\checkmark$ & $\checkmark$ & $\checkmark$ & \\
\hline 22 & Natural tragedies & & $\checkmark$ & & & \\
\hline 23 & Variation in prices & $\checkmark$ & $\checkmark$ & $\checkmark$ & $\checkmark$ & \\
\hline 24 & Legal arguments & & & & & $\checkmark$ \\
\hline 25 & Difference order & & $\checkmark$ & & & $\checkmark$ \\
\hline 26 & Inconsistencies in contract forms & $\checkmark$ & & $\checkmark$ & & \\
\hline 27 & Improper organization of supplies & $\checkmark$ & & & & \\
\hline 28 & Transport conditions & $\checkmark$ & & & & \\
\hline
\end{tabular}

value of this catalogue designates a superior significance of the postponement factor.

\section{ESEARCH METHODOLOGY}

The projected model starts with studying the literature connected to the chief reasons for the postponement in constructing segment. Afterwards that, the composed features are assessed by dispensing, assembling, and analyzing the questionnaire surveys amongst various specialists in the constructing part (i.e. owners, consultants, and contractors). Additionally, data examination is employed to rank the postponement issues utilizing the relative importance index. Lastly, the probable events that might be occupied to prevent postponements in construction schemes are deliberated.

$$
\boldsymbol{R I I}=\frac{\sum \boldsymbol{W}}{\boldsymbol{A} * \boldsymbol{N}}
$$

Where; signifies the grade assumed to every issue by the defendant, displays the uppermost weight, and signifies the total quantity of answers. It might be distinguished that an advanced

\section{A. Data Collection}

An introductory list of the most essential delay factors in constructing a building was recognized built on a wide literature review, which can be seen in the summarized TABLE I. The causes of the postponement might be characterized into an owner, consultant, contractor, material, labour and equipmentcorrelated, and external-correlated groups. The owner-related class covers postponement in reviewing the documents, late compensation for the accomplished work. Not on-time decision making, inappropriate organization of owner, and differentiate instruction. The consultant-related issues include mistakes in design, design variations, mistakes in soil examination, and postponement in positive shop drawings.

The contractor-related issues include the financial difficulties of the contractor, poor site organization, mistakes in construction, and postponement in making shop sketches. The material-related grouping comprises the late distribution of 
resources, lack of materials, and inappropriate management of resources. The labour and equipment-related issues contain poor manufacture rate of works, lack of apparatus and efforts, and untrained efforts. The exterior connected aspects contain inappropriate organization between project parties, conflicts between project parties, transportation circumstances, bad weather conditions, natural disasters, variation in prices, changes in the contract, legal arguments, and inconsistencies in contract forms.

The explanations for every postponement feature are added TABLE I. The composed features are then assessed by showing twenty-six questionnaire surveys amongst a wide range of specialists in building construction manufacturing. These specialists are arranged to render their know-how into three classes namely, owner, consultant, and contractor.

The structure of the survey contains three parts: knowledgeable agreement form, respondent's info, and requests about features touching postponement in the construction industry as well as their justification actions.

The agreement procedure notifies the member about the aim of the work and the profits of involvement. In the wide-ranging info portion, the contributors are requested about their titles, job, and years of knowledge. The specialists are demanded in the previous portion of the survey to explain the relative significance of the postponement reasons in the Egyptian constructing industry. The specialists shall explain their favourites lingually rendering to a scale, which varieties from "1", which describes the lowest impact, to "5", which means the highest impact. Lastly, the specialists are demanded to endorse the imaginable movements to moderate these worries.

\section{B. Results and discussion}

Several causes of postponement in the Kurdistan building construction projects have been investigated. This explains the need of concentrating on the greatest key difficulties inside the construction industry and the chances for monitoring and decreasing project postponements. The documentation of postponement issues is approved out over the main datagathering technique (i.e. literature review). As specified before, twenty-eight features are recognized and gathered in three groups. The important stages of these postponement issues are noticed using RII through questionnaire surveys.

The RII of every feature is considered by identifying magnitudes to the obtainable choices in the questionnaire; 1 to "not at all important", 2 to "of little importance", 3 to "moderately important", 4 to "important", and 5 to "very important". The RII of the postponement features in the constructing plans in the Kurdistan region of Iraq has been used. It is originated that the greatest five powerful postponement issues are monetary difficulties by contractor, variation in prices, postponement in formulating and approving shop sketches, lack of workers, and errors in soil examination. On the other side, the five least significant reasons for postponement are alterations in contract, inappropriate organization of owner, inappropriate organization of resources, bad climate circumstances, and lawful arguments

Additionally, the suggested movements to circumvent the reasons for scheme postponements are itemized in this unit.
From the owner's viewpoint, the subsequent activities should be occupied: a) agreeing on a comprehensive and real project period in the contract, b) guaranteeing the obtainability of the vital funds, c) Preparing due to expenditures to the contractor for the finished works, d) Explaining the possibility of work suitably, e) signing a knowledgeable servicer with a respectable repute, f) commence with a high expert and good reputation consultant, g) making a precise viability study and monetary strategy, h) obtaining the desirable endorsements from the related establishments, and i) making whole, precise, and unmistakable tender forms. Up to contractor viewpoint, the subsequent opinions should be fulfilled: a) directing an understandable cash flow investigation, b) Preparing a suitable choice of subcontractors built on experiences and knowledge, c) guaranteeing well-organized workplace managing and direction, d) adding working out to the labours to advance their assistances, e) utilizing contemporary technologies in the workplace, f) applying health and safety rules on-the workplace, and g) Supervising and broadcasting any reasons of postponements in the constructing place.

For the consultants, the subsequent developments of activities must be completed: a) assessing and monitoring difference instructions, b) preventing postponement to the contractor's enquiries, and c) complimenting the acquiesced shop sketches on time. Lastly, it might be experiencing that appropriate relation and management between project gatherings, clear documentation of the parts and responsibilities of project investors are registered as the important movements that might be assumed to alleviate the postponement causes.

\section{CONCLUSION}

This paper studied the key reasons for postponements in the Kurdistan construction building projects. The initial list of postponement causes was recognized built on a wide literature review. After that, the proposed features were then examined by presenting questionnaire studies amongst construction experts. The responses feedback was assessed using the relative importance index method. It was discovered that the five main important postponement features are monetary difficulties by contractor, variation in prices, postponement in making and approving shop sketches, lack of workers, and mistakes in soil examination. On the other hand, the five least important postponement aspects are alteration in contract, inappropriate organization of owner, poor organization of resources, bad climate circumstances, and legal arguments. The investigation also suggested the probable approaches of dropping project postponements. This suggests that construction frontline companies must pay care to the greatest mutual features producing postponements in the Kurdistan constructing schemes with admiration to their scales of impact. Furthermore, the answers of this investigation offer scheme investors suitable answers for disputing any postponements. This will eventually result in the discount of resources, time and currency with better presentation of building projects, which recovers the state's economy. 


\section{REFERENCES}

[1] S. Neamat, "The Development Of Management Control Systems Framework In Public-Private Partnerships," International Journal of Scientific \& Technology Research, vol. 8, no. 10, Art. no. 10, 2019.

[2] S. Neamat, "A Developed Framework for Energy Technology Sustainability Assessment,” Int. J. Innov. Technol. Explor. Eng. IJITEE, vol. 9, no. 1, pp. 832-838, 2019.

[3] M. Birgönül, I. Dikmen, and B. Ozorhon, "The impact of reverse knowledge transfer on competitiveness: The Case of Turkish Contractors in Economics for the Modern Built Environment., Les Ruddock," 2009.

[4] S. A. Assaf and S. Al-Hejji, "Causes of delay in large construction projects," International journal of project management, vol. 24, no. 4, pp. 349-357, 2006.

[5] A. S. Faridi and S. M. El - Sayegh, "Significant factors causing delay in the UAE construction industry," Construction Management and Economics, vol. 24, no. 11, pp. 1167-1176, 2006.

[6] M. H. Fallahnejad, "Delay causes in Iran gas pipeline projects," International Journal of project management, vol. 31, no. 1, pp. 136-146, 2013.

[7] S. Neamat, "Investigation of FRP impact on Shear Strengthening of Reinforced and Pre-Stressed Concrete Beams," research review, vol. 9, p. 11, 2020.

[8] S. Neamat, "Factors Affecting Project Performance in Kurdistan Region of Iraq," International Journal of Advanced Engineering Research and Science, vol. 4, no. 5, pp. 01-05, 2017.

[9] P. Shahsavand, A. Marefat, and M. Parchamijalal, "Causes of delays in construction industry and comparative delay analysis techniques with SCL protocol," Engineering, Construction and Architectural Management, 2018

[10] S. Sivaprakasam, S. Dinesh, and J. Jayashree, 'A review on causes of delay in construction projects', IJSRD, vol. 5, no. 2, pp. 1108-1110, 2017".

[11] P. Turkar and M. Apte, "Delay Causes and Importance of Corrective Actions on them," 2016.

[12] S. D. Salahaddin, "Factors Affecting the Competitiveness and Innovation in Northern Iraq Construction Industry," 2016.

[13] S. S. Mulla and A. P. Waghmare, "A study of factors caused for time \& cost overruns in construction project \& their remedial measures," International Journal of Engineering Research and Applications, vol. 5, no. 1, pp. 48-53, 2015.

[14] S. Neamat, "Human Resource Management with Strategic Development," Journal of Civil Engineering Frontiers, vol. 1, no. 1, pp. $16-19,2020$.

[15] S. Neamat and M. Shamsborhan, "The Investigation of The Different Types of the Ground Rebar Spacers with Proposing New Design Rebar
Space Mixed of Concrete Plastic," Journal of Civil Engineering Frontiers, vol. 1, no. 1, pp. 01-06, 2020.

[16] A. Muhammed, H. Karimi, B. Gharab, S. Neamat, and K. Mirzaei, "Assessment of the Quality of the Environment in Duhok Province, Kurdistan Region of Iraq," Journal of Civil Engineering Frontiers, vol. 1, no. 1, pp. 20-24, 2020.

[17] S. Neamat and H. Karimi, "A systematic review of GIS-based landslide Hazard Mapping on Determinant Factors from International Databases," in 2020 International Conference on Advanced Science and Engineering (ICOASE), Dec. 2020, pp. 180-183. doi: 10.1109/ICOASE51841.2020.9436611.

[18] S. Neamat, "Management Controls For Minimizing Risk In PublicPrivate Partnerships In Kurdistan Region Of Iraq".

[19] T. Gebrehiwet and H. Luo, "Analysis of delay impact on construction project based on RII and correlation coefficient: Empirical study," Procedia engineering, vol. 196, pp. 366-374, 2017.

[20] S. Neamat, "Models Developed for Creep of High Strength Concrete," International Journal of Civil,Mechanical and Energy Science, vol. 3, no. 3, pp. 174-180, May 2017.

[21] H. Karimi, S. Neamat, and S. Galali, "Application of Mathematical Matrices for Environmental Impact Assessment, A Case Study of Thermal Power Plant," Journal of Applied Science and Technology Trends, vol. 1, no. 1, pp. 13-16, 2020.

[22] J. K. Larsen, G. Q. Shen, S. M. Lindhard, and T. D. Brunoe, "Factors affecting schedule delay, cost overrun, and quality level in public construction projects," Journal of Management in Engineering, vol. 32, no. 1, p. $04015032,2016$.

[23] S. D. S. Neamat, "A Comparative Study of Safety Leading and Lagging Indicators Measuring Project Safety Performance," Adv. Sci. Technol. Eng. Syst. J., vol. 4, no. 6, pp. 306-312, 2019.

[24] S. Durdyev, M. Omarov, and S. Ismail, "Causes of delay in residential construction projects in Cambodia," Cogent Engineering, vol. 4, no. 1, p. 1291117, 2017.

[25] S. Neamat, "Risk Assessment for Uzun Construction and Real Estate Company in TRNC".

[26] S. Neamat and I. Yitmen, "Factors Affecting the Innovation and Competitiveness in Kurdistan Region of Iraq Construction Industry," International Journal of Advanced Engineering Research and Science (IJAERS), vol. 4, no. 2, pp. 157-162, 2017, doi: https://dx.doi.org/10.22161/ijaers.4.2.31.

[27] E. Soliman, "Recommendations to Mitigate Delay Causes in Kuwait Construction Projects," American Journal of Civil Engineering and Architecture, vol. 5, no. 6, pp. 253-262, 2017. 